\title{
URETHRAL PLICATION IN THE MANAGEMENT OF URINARY INCONTINENCE*
}

\author{
BY
}

\author{
D. F. ELLISON NASH \\ From St. Bartholomew's Hospital, London
}

The operation of urethral plication is based upon the procedures described by Lowsley and Kirwin (1944) and later by Millin (1947) for the treatment of post-prostatectomy incontinence. The procedure used in children (Nash, 1957) is a relatively small operation with a low risk and a very low complication rate. Three widely spaced mattress sutures of floss nylon are inserted from the ischio-cavernosus muscle on one side to that on the other in such a way that they compress from below upwards the urethra and the defective bulbo-spongiosus muscle against the triangular ligament. This manoeuvre diminishes the calibre of the bulbous urethra so that the mucosal folds may be more adequately opposed by what muscle action remains. In addition, I believe that the reduction of this large reservoir of urine in the bulb is an advantage in preventing infection. In paraplegic cases the urethra and the perineal tissues are insensitive, and if the stitches are inserted too tightly there is a risk of necrosis and fistula formation. The sites of suture contain erectile tissue and haemorrhage may be troublesome during the operation. Diathermy is essential. A No. 9E. rubber catheter is inserted for the duration of the operation, and a Gibbon's Portex catheter is left in situ for 24 hours post-operatively.

Application of the Operation. The operation has been performed in 21 cases of incontinence in childhood. These have been followed up for periods of two to 10 years. On six occasions the operation was performed in enuretic boys whose night incontinence was lifelong, and in whom there seemed to be no functional explanation for the disorder. One was 'cured', two were improved and the others unaffected. In one of those unaffected the bulbo-spongiosus muscle was found to be unilateral at operation.

The second group consists of 14 children with congenital spinal palsy, 13 due to spina bifida and

- A paper read at the meeting of the British Association of Paediatric Surgeons held in London in July, 1958. one to sacral agenesis. This last child was cured. Of the 13 with spina bifida four had had suprapubic cystostomies, heavy infection and gross pelvic deformity. One of these boys (B.H.) had nearly died with pyelonephritis on several occasions. A lifesaving suprapubic cystotomy resulted in a very good recovery in his general health, but the continuous dribbling of urine from the urethra, associated with a bilateral below-knee amputation made life very difficult. Urethral plication was performed without a catheter in position and with the sutures tight. This completely occluded the urethra and prevented any further leakage. Owing to the recurrence of pyelonephritis, with the suprapubic cystotomy, 10 years after the initial operation the perineum was explored, the sutures removed and the urethra found to be intact. Curiously enough the boy is now free from any retention, his suprapubic sinus has healed, and he can void urine satisfactorily with only a minor degree of leakage in between. For this he wears a light-weight urinal. The operation is thus a very satisfactory method of closing the urethra, permanently or temporarily in the very rare instances in which a suprapubic cystostomy is necessary. In the other three boys who have suprapubic drainage the operation was tried after the cystostomy had healed, but was unsuccessful.

Nine other boys were selected for operation on the basis of the following criteria:

Residual urine was not more than $1 \mathrm{oz}$, and there was no evidence of back pressure changes in the ureters or kidneys. Diverticulation of the bladder was not necessarily a contraindication. The bladder was capable of being distended and had a capacity of at least $3 \mathrm{oz}$.

Very few of these children have a spastic or systolic bladder, but if such a condition is present the operation is unlikely to be of any use. If the child already has some degree of control, for instance if he can pass several ounces naturally although he is incontinent as well, the operation is most likely to succeed and is always worth tyying. 
Two of these boys were given complete control; in four the condition greatly improved and became manageable and in three there was no change.

The other boy who had had bladder neck resection performed twice for urinary obstruction (fibroelastosis) had persistent incontinence following the resections. Normal control has been restored though there has been a very occasional leak during vigorous physical stress such as football.

\section{Summary}

If the operation is applied in cases selected upon the criteria outlined above, for children with incon- tinence arising from spina bifida, sacral agenesis or fibro-elastosis, there is a very good chance of restoring continence. In fact four out of the 11 boys were cured of their incontinence, four were improved and in three there was no change. A chance of removing this troublesome complaint from a boy who had to struggle around in double calipers was thought to be well worth taking.

REFERENCES

Lowsley, O. S. and Kirwin, T. J. (1944). Clinical Urology. Williams and Wilkins, Baltimore.

Millin, T. (1947). Retropubic Urinary Surgery. Livingstone, Edinburgh.

Nash, D. F. E. (1957). Ann. roy. Coll. Surg. Engl., 20, 349. 